\title{
The Current Status of Nodal Staging in Rectal Cancer
}

\author{
Amy Lord ${ }^{1,2} \cdot$ Nigel $D^{\prime}$ Souza ${ }^{1,2} \cdot$ Annabel Shaw ${ }^{1,2} \cdot$ Nigel Day $^{1,2} \cdot$ Gina Brown ${ }^{1}$
}

Published online: 28 August 2019

(C) The Author(s) 2019

\begin{abstract}
Purpose of Review To review current practice in MRI-based nodal staging in rectal cancer and assess the associated evidence. Recent Findings Nodal staging is less accurate than other MRI-detected prognostic markers such as circumferential resection margin status, extramural venous invasion and T stage. Previous research has focused on matching MRI and pathology findings but crucially $\mathrm{N}$ stage has never been shown to have prognostic importance on MRI. Recent pathological evidence suggests that tumour deposits may be more important than nodal status and these can be clearly distinguished from nodal metastases on MRI. Summary Nodal staging on MRI is prognostically inaccurate. MRI staging should move away from TNM to focus on those radiological markers which can be proved to have prognostic accuracy. Tumour deposits should be reported separately to lymph node metastases on both histopathology and imaging. Research is underway confirming their prognostic importance on MRI.
\end{abstract}

Keywords Rectal cancer $\cdot$ MRI $\cdot$ Staging $\cdot$ Lymph nodes $\cdot$ Tumour deposits $\cdot$ Prognosis

\section{Introduction}

Pre-operative staging is an essential aspect of the management of rectal cancer and radiological assessment with magnetic resonance imaging (MRI) plays a key role in this process. As well as defining the anatomy of the tumour and determining surgical strategy by assessing whether safe surgical margins can be achieved, radiological assessment should ideally provide additional prognostic information to separate patients into high- and low-risk groups in order to determine whether they are likely to benefit from neo-adjuvant therapy to reduce their risk of local and distant failure.

Radiological staging currently aims to predict the pathological TNM stage as this is thought to be closely linked to prognosis. The presence of MRI-predicted lymph node metastases (mrLNM) upstages a patient from stage II to stage III and

This article is part of the Topical Collection on Diagnostic and Interventional Radiology Innovations in Colorectal Cancer

Gina Brown

gina.brown@rmh.nhs.uk

1 Department of Gastrointestinal Radiology, Royal Marsden NHS Foundation Trust, Downs Road, Sutton, Surrey SM2 5PT, UK

2 Department of General Surgery, Croydon University Hospital, 530 London Road, Croydon, London CR7 7YE, UK therefore may play a key role in the perception of a 'high-risk' tumour and the decision to utilize pre-operative chemoradiotherapy, although which patients to treat remains controversial and subject to widespread variation in practice.

This article aims to review the evidence surrounding the ability of MRI to accurately diagnose LNM and furthermore outlines our current understanding of the pathways of spread to metastatic disease in rectal cancer which raises questions as to the importance of LNM in this process.

\section{The History of Lymph Node Staging}

Current pathological TNM staging appears to be suboptimal as it fails to stratify patients adequately. Several studies have shown that those who are staged as IIB/C $(\mathrm{T} 4 \mathrm{a} / \mathrm{b}, \mathrm{N} 0)$ have a significantly worse prognosis than those staged IIIA (T1-2, $\mathrm{N} 1$ or T1,N2a) [1-3]. It appears that perhaps LNM are being weighted too heavily when either T stage, or indeed other factors not included in TNM, are better predictors of survival.

The presence of tumour within lymph nodes (LN) was first reported as a marker of poor prognosis by LockhartMummary [4] and later by his colleague Dukes [5], leading to the well-known Dukes staging system. They reported only a $7 \%$ survival rate in patients with tumour in the regional lymph nodes (Dukes C) compared with $73 \%$ in those without 
(Dukes B) [5]. The AJCC/UICC tumour nodes metastases (TNM) system is an adaptation of this with some modifications and sub-classifications but the same basic principles [6]. TNM previously classified patients as N0, N1 or N2 according to the number of lymph nodes involved [7]; however, with recent TNM editions, this has become more complicated, particularly with the addition of the N1c subcategory [8] which is used for tumour deposits (TD) of non-nodal origin (but rather confusingly is still part of the $\mathrm{N}$ stage).

There is currently ongoing controversy amongst the pathology community about the separation of LNM from TD, which are defined as nodules of tumour within the mesorectum without evidence of underlying lymph node architecture. TD have been recognised since the 1930s [5] as a separate entity to LNM but interest in them reignited in the late 1990s when they were first officially recognised in the TNM system [9] and several publications highlighted their importance in predicting poor prognosis [10-12]. Multiple studies, and two recent meta-analyses $[13,14 \bullet]$, have now shown that TD seen on pathology are associated with a worse prognosis than LNM but until recently they have been reported as a single entity and there are significant problems with interobserver variation and widely varying reports of prevalence in the literature [13, 15]. The recognition that TD are prognostically worse than LNM has not yet been reflected in the TNM system, with their presence currently only being reported in node negative cases and with their placement in the prognostic hierarchy below N2 disease.

\section{Assessment of Lymph Nodes on MRI}

In the past, nodal staging on MRI has relied on the measurement of LN with the assumption that larger LN would contain tumour. Despite evidence that there is a great degree of overlap in the size of involved and non-involved LN [16-18] and the fact that no cut-off size has ever been universally agreed, a focus on measuring LN still persists within the radiology community. While radiologists regard enlarged $\mathrm{LN}$ as an indicator of malignancy, in contrast, in histopathological studies, the presence of numerous large LN has actually been recognised as a good prognostic marker in a number of studies, possibly as a result of an appropriate immune response to the tumour which confers a survival advantage [17-19]. Morphological predictors of nodal involvement, namely mixed signal intensity and irregular borders, have been shown to have greater accuracy than LN size (sensitivity $85 \%$ and specificity $97 \%$ [16] vs sensitivity $67 \%$ and specificity $83 \%$ if a 5 -mm cut-off is used [20]). However, it is likely that this definition included TD in the past which would also have had irregular borders and were likely to have been classified as LNM on pathology. Figures 1 and 2 show LN which would be classified as benign and malignant respectively using morphological criteria.
Generally, MRI sensitivity and specificity for LNM is only moderate and MRI has a tendency to overstage within the nodal category [20-23] compared with pathology. A recent large retrospective study showed a sensitivity of only $38 \%$, a specificity of $87 \%$ and a positive predictive value of $56 \%$ for the diagnosis of LNM on MRI compared with pathology, which the authors compared with flipping a coin [24•]. Nodal status is less well seen on MRI than other prognostic markers. A 2012 meta-analysis found a poor diagnostic odds ratio of 8.3 (4.6-14.7) for the detection of mrLNM compared with $20.4(11.1-37.3)$ for mrT stage and 56.1 (15.3-205.8) for mrCRM status [25].

Nodal status on MRI has never been proven as an independent marker of poor prognosis in the same way that MRIdetected EMVI and CRM status has been [26, 27]. Multiple studies have examined the diagnostic accuracy of MRI in comparing nodal status on MRI with that of pathology, the gold standard; however, the prognostic accuracy has never been proven. Matching what will be seen on pathology is only useful if this influences survival outcomes.

\section{Separating Lymph Node Metastases From Tumour Deposits on MRI}

TD have a very different appearance to LNM on MRI (Fig. 3) and, in our institution, are seen very commonly with a prevalence of around $40 \%$. We define them as nodules of tumour within the mesorectum which appear to directly interrupt the course of a vein (as opposed to lymph nodes which may be located adjacent to veins but will not interrupt their course when seen on two orthogonal views). In our experience, we have observed that TD are very closely related to EMVI but appear to be a more severe manifestation with distinct nodules which are discontinuous from the primary tumour mass. We have observed that they have a particularly poor prognosis. As on pathology, TD are likely to have a prognostic effect which is worse than that of LNM and as such should be reported separately.

Currently, radiologists are required to use the term ' $\mathrm{n} 1 \mathrm{c}$ ' to describe TD seen on MRI in order to fit in with current TNMbased reporting; however, this is confusing and does not reflect their true origin or position in the prognostic hierarchy, as the $\mathrm{N} 1$ designation implies that they are prognostically better than N2 disease. Furthermore, if they are only reported in the absence of LNM, as stipulated by TNM, important prognostic information will be lost.

\section{Pathways of Metastatic Spread}

The long-recognised correlation between the presence of LNM and poor survival has in the past been assumed to be 
Fig. 1 MRI scan showing benign lymph nodes according to morphological criteria (arrows)

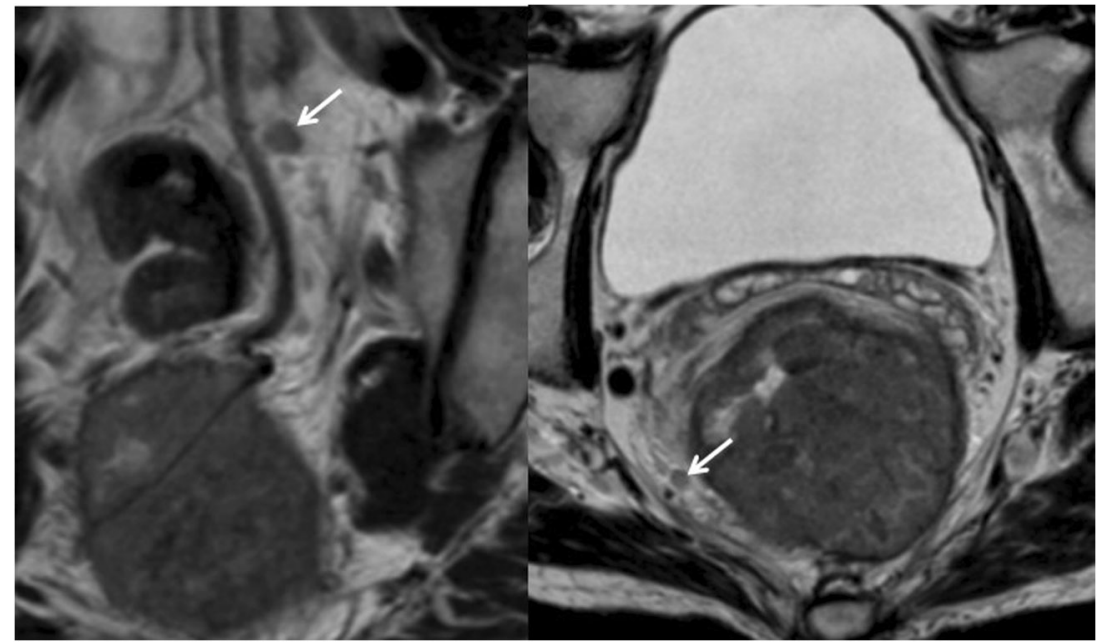

causation. More recently, questions have been raised as to whether this is truly the case. LNM are more common in patients who also have increased depth of invasion and EMVI and, furthermore, nodules previously reported as LNM may in many cases have been TD.

Local recurrence has been a major problem in the past but this has changed considerably following the recognition that the entire mesorectum should be removed en bloc with the tumour with a total mesorectal excision (TME) procedure [28]. Predicting whether surgical margins will be safe using MRI has also been instrumental in reducing local recurrence rates [29]. Accurate pre-operative assessment and highquality surgery have reduced local recurrence rates from around 20 to around 5\% [30]. Furthermore, local recurrence rates are comparable (6\% vs 5\%) in those with LNM with those who are node negative as long as a good-quality TME is performed [30].

The liver is the most common site of distant metastasis; however, there is no direct route for tumour within LN to gain access to the portal circulation. It seems far more likely that tumour is gaining access via the veins (i.e. EMVI and TD) than taking a circuitous route via the lymphatics and thoracic duct which would not end at the liver. There is increasing evidence to support this hypothesis. Knijn carried out two studies investigating the link between LNM and distant metastases; the first was an autopsy study which showed no association between LNM and liver metastases [31]; the second looked at the KRAS status of primary tumour, LNM and liver metastases and found that while the primary tumour and liver metastases had concordant KRAS mutation status, the tumour in LNM was discordant and therefore was unlikely to be involved in the metastatic pathway [32]. More recently, Naxerova et al. [33•] went a step further and examined the clonal concordance of tumour in these locations. They similarly found that the majority of LNM were of different phylogenetic origin to liver metastases. The simple mechanistic view of primary tumour seeding to LNM and then on to distant metastases is most likely incorrect, and one must therefore question whether LNM are simply a bystander in the metastatic process. LNM may indicate a phenotypically aggressive tumour with the means to spread but may be an end result of this spread rather than a step on the metastatic pathway.
Fig. 2 MRI scan showing malignant lymph nodes according to morphological criteria (arrows)

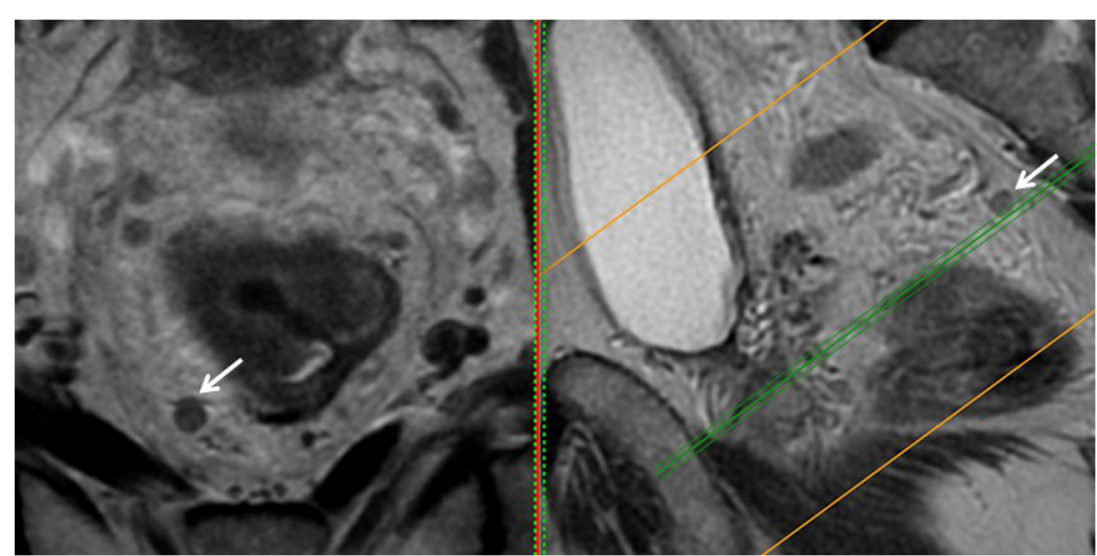


Fig. 3 MRI scans showing the appearance of tumour deposits (arrows)

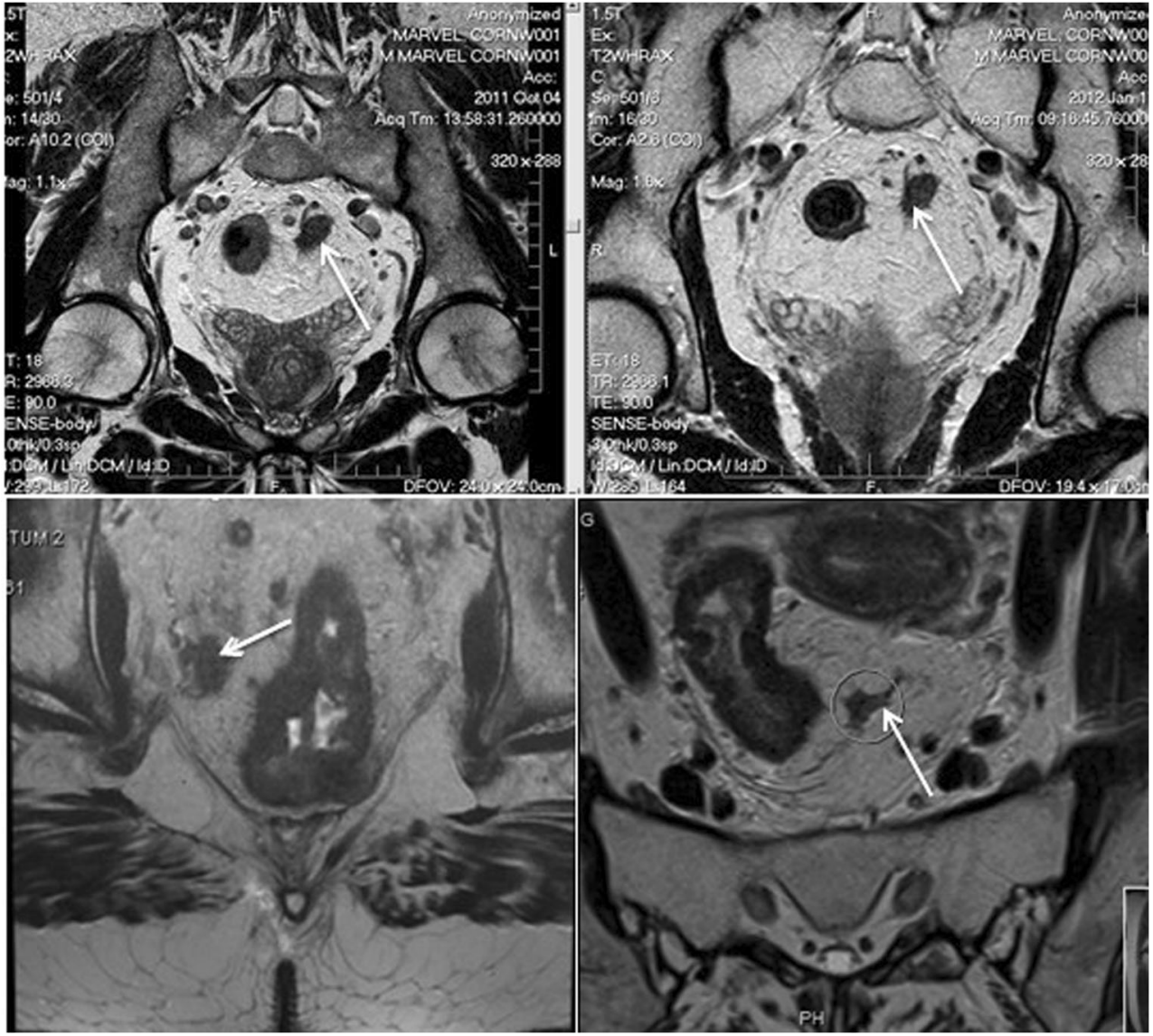

\section{Discussion}

Recently, questions are being raised as to how important LNM really are in the development of recurrence $[31,32,33 \cdot, 34$, 35], in particular in the development of distant metastases, and whether other MRI-detected prognostic marker such as extramural venous invasion (EMVI) is more important. The TNM system does not adequately include factors such as the presence of EMVI or the status of the circumferential resection margin (CRM) which have been shown to be extremely important prognostic markers. In contrast, nodal status on MRI has never been proven to have prognostic accuracy but still forms a major part of staging. By using the TNM system, we may be losing prognostic power and we believe that a major reappraisal of MRI staging is needed.

In our practice, we focus on reporting mrEMVI and mrTD rather than mrLNM. We continue to use the term 'mrN1c' as stipulated by the TNM system but this supersedes the presence of mrLNM due to the association with worse prognosis seen on pathology and our own observations that mrTD are associated with very poor prognosis (manuscript submitted). We have observed that if there are nodal metastases in the absence of mrTD or mrEMVI, and the patient is undergoing good-quality TME surgery, this is not a poor prognostic marker. The prognostic significance of TD seen on MRI and the correlation between the diagnosis of TD on MRI and pathology are the subjects of the COMET trial [36] which is currently in progress.

In conclusion, we feel that the radiology community should be focusing on features seen on MRI which can be proven as independent markers of poor prognosis rather than trying to predict pathology findings. The TNM system provides suboptimal prognostic stratification even in pathology and has never truly been evaluated for MRI. Distinguishing the true markers of poor prognosis which allow us to separate patients into high- and low-risk groups on MRI will allow us to make evidence-based treatment decisions and have honest discussions with patients about their level of risk and the potential risks and benefits of neo-adjuvant therapy.

\section{Compliance with Ethical Standards}

Conflict of Interest The authors declare that they have no conflict of interest.

Human and Animal Rights and Informed Consent This article does not contain any studies with human or animal subjects performed by any of the authors. 
Open Access This article is distributed under the terms of the Creative Commons Attribution 4.0 International License (http:// creativecommons.org/licenses/by/4.0/), which permits unrestricted use, distribution, and reproduction in any medium, provided you give appropriate credit to the original author(s) and the source, provide a link to the Creative Commons license, and indicate if changes were made.

\section{References}

Papers of particular interest, published recently, have been highlighted as:

\section{- Of importance}

1. Mo S, Dai W, Xiang W, Huang B, Li Y, Feng Y, et al. Survival contradiction between stage IIA and stage IIIA rectal cancer: a retrospective study. J Cancer [Internet]. Ivyspring International Publisher; 2018 [cited 2019 Feb 25];9(8):1466-75. Available from: http://www.ncbi.nlm.nih.gov/pubmed/29721057.

2. Li J, Yi C-H, Hu Y-T, Li J-S, Yuan Y, Zhang S-Z, et al. TNM Staging of colorectal cancer should be reconsidered according to weighting of the T stage: verification based on a 25-year follow-up. Medicine (Baltimore) [Internet]. Wolters Kluwer Health; $2016 \mathrm{Feb}$ [cited $2019 \mathrm{Feb} 25$ ];95(6):e2711. Available from: http://www.ncbi. nlm.nih.gov/pubmed/26871810.

3. Nitsche U, Maak M, Schuster T, Künzli B, Langer R, SlottaHuspenina $\mathbf{J}$, et al. Prediction of prognosis is not improved by the seventh and latest edition of the TNM classification for colorectal cancer in a single-center collective. Ann Surg [Internet]. 2011 Nov [cited 2016 Dec 1];254(5):793-801. Available from: http://content. wkhealth.com/linkback/openurl?sid=WKPTLP:landingpage $\& a n=$ 00000658-201111000-00017.

4. Lockhart-Mummery JP. Two hundred cases of cancer of the rectum treated by perineal excision. Br J Surg [Internet]. John Wiley \& Sons, Ltd.; 1926 Jul 1 [cited 2017 Sep 5];14(53):110-24. Available from: http://doi.wiley.com/10.1002/bjs.1800145312.

5. Gabriel WB, Dukes C, Bussey HJR, et al. Lymphatic spread in cancer of the rectum. Br J Surg [Internet]. 1935 Oct [cited 2016 Jun 13];1(23):395. Available from: http://onlinelibrary.wiley.com/ doi/10.1002/bjs.1800239017/abstract

6. Amin MB, Edge SB, American Joint Committee on Cancer. AJCC cancer staging manual. 8th ed: Springer International Publishing; 2017. $1024 \mathrm{p}$

7. Sobin LHWC, editor. International Union Against Cancer TNM classification of malignant tumours. ed 6 ed. Hoboken: Wiley; 2002.

8. Sobin LH, Gospodarowicz MWC, editors. International Union Against Cancer TNM classification of malignant tumours. ed 7 ed. Hoboken: Wiley-Blackwell; 2009.

9. Sobin LH, Fleming ID. TNM classification of malignant tumors, fifth edition (1997). Cancer [Internet]. John Wiley \& Sons, Ltd; 1997 Nov 1 [cited 2019 Apr 2];80(9):1803-4. Available from: http://doi.wiley.com/10.1002/\%28SICI\%291097-0142\% $2819971101 \% 2980 \% 3$ A9\%3C1803\%3A\%3AAID-CNCR16\% 3E3.0.CO\%3B2-9.

10. Goldstein NS, Turner JR. Pericolonic tumor deposits in patients with $\mathrm{T} 3 \mathrm{~N}+\mathrm{M} 0$ colon adenocarcinomas: markers of reduced disease free survival and intra-abdominal metastases and their implications for TNM classification. Cancer. 2000;88(10):2228-38.

11. Prabhudesai A, Arif S, Finlayson CJ, Kumar D. Impact of microscopic extranodal tumor deposits on the outcome of patients with rectal cancer. Dis Colon Rectum. 2003;46(11):1531-7 Available from: http://ovidsp.ovid.com/ovidweb.cgi?T=JS\&CSC= $Y \& N E W S=N \& P A G E=$ fulltext\&D=emed6\&AN=2003472990.

12. Singh AK, Myerson RJ, Birnbaum EH, Fleshman JW, Kodner IJ, Lockett MA, et al. Outcome of patients with rectal adenocarcinoma and localized pelvic non-nodal metastatic foci. Dis Colon Rectum [Internet]. 2000 Sep [cited 2016 Jun 13];43(9):1217-21. Available from: http://ovidsp.ovid.com/ovidweb.cgi?T=JS\&CSC= $Y \& N E W S=N \& P A G E=$ fulltext\&D=emed5\&AN=2000330824.

13. Lord AC, D'Souza N, Pucher PH, Moran BJ, Abulafi AM, Wotherspoon A, et al. Significance of extranodal tumour deposits in colorectal cancer: a systematic review and meta-analysis. Eur J Cancer [Internet]. 2017 Sep 23 [cited 2017 Jun 27];82:92-102. Available from: http://www.ncbi.nlm.nih.gov/pubmed/28651160.

14. Nagtegaal ID, Knijn N, Hugen N, Marshall HC, Sugihara K, Tot T, et al. Tumor deposits in colorectal cancer: improving the value of modern staging - a systematic review and meta-analysis. J Clin Oncol. 34 This meta-analysis proved that TD are a worse prognostic factor than LNM on histopathology. This finding should prompt radiologists to similarly differentiate between the two entities on imaging.

15. Rock JB, Washington MK, Ph D, Adsay V, Joel K, Montgomery EA, et al. Debating deposits: an inter-observer variability study of lymph nodes and pericolonic tumor deposits in colonic adenocarcinoma. 2014;138(5):636-642.

16. Brown G, Richards CJ, Bourne MW, Newcombe RG, Radcliffe AG, Dallimore NS, et al. Morphologic predictors of lymph node status in rectal cancer with use of high-spatial-resolution MR imaging with histopathologic comparison. Radiology [Internet]. 2003 May [cited 2017 May 17];227(2):371-7. Available from: http:// www.ncbi.nlm.nih.gov/pubmed/12732695.

17. Märkl B, Schaller T, Kokot Y, Endhardt K, Kretsinger H, Hirschbühl K, et al. Lymph node size as a simple prognostic factor in node negative colon cancer and an alternative thesis to stage migration. Am J Surg [Internet]. 2016 Oct [cited 2019 Feb 25];212(4):775-80. Available from: http://www.ncbi.nlm.nih. gov/pubmed/26307422.

18. Märk1 B, Wieberneit J, Kretsinger H, Mayr P, Anthuber M, Arnholdt HMet al. Number of intratumoral T lymphocytes is associated with lymph node size, lymph node harvest, and outcome in node-negative colon cancer. Am J Clin Pathol [Internet]. 2016 Jun [cited 2019 Feb 25];145(6):826-36. Available from: http://www. ncbi.nlm.nih.gov/pubmed/27329640.

19. Märkl B. Stage migration vs immunology: the lymph node count story in colon cancer. World J Gastroenterol [Internet]. Baishideng Publishing Group Inc; 2015 Nov 21 [cited 2017 Jun 28];21(43): 12218-33. Available from: http://www.ncbi.nlm.nih.gov/pubmed/ 26604632.

20. Doyon F, Attenberger UI, Dinter DJ, Schoenberg SO, Post S, Kienle P. Clinical relevance of morphologic MRI criteria for the assessment of lymph nodes in patients with rectal cancer. Int $\mathrm{J}$ Color Dis [Internet]. 2015 Nov 11 [cited 2019 Feb 25];30(11):1541-6. Available from: http://www.ncbi.nlm.nih.gov/pubmed/26260478.

21. Park JS, Jang Y-J, Choi G-S, Park SY, Kim HJ, Kang H, et al. Accuracy of preoperative MRI in predicting pathology stage in rectal cancers. Dis Colon Rectum [Internet]. 2014 Jan [cited 2019 Feb 26];57(1):32-8. Available from: http://content.wkhealth.com/ linkback/openurl?sid=WKPTLP:landingpage $\& a n=00003453$ 201401000-00005.

22. Li X-T, Sun Y-S, Tang L, Cao K, Zhang X-Y. Evaluating local lymph node metastasis with magnetic resonance imaging, endoluminal ultrasound and computed tomography in rectal cancer: a meta-analysis. Color Dis [Internet]. John Wiley \& Sons, Ltd (10.1111); 2015 Jun 1 [cited 2019 Feb 26];17(6):O129-35. Available from: http://doi.wiley.com/10.1111/codi.12909.

23. Kim NK, Kim MJ, Park JK, Park SI, Min JS. Preoperative staging of rectal cancer with MRI: accuracy and clinical usefulness. Ann 
Surg Oncol [Internet]. 2000 Dec [cited 2019 Feb 26];7(10):732-7. Available from: http://www.ncbi.nlm.nih.gov/pubmed/11129420.

24. Brouwer NPM, Stijns RCH, Lemmens VEPP, Nagtegaal ID, BeetsTan RGH, Fütterer JJ, et al. Clinical lymph node staging in colorectal cancer; a flip of the coin? Eur J Surg Oncol [Internet]. W.B. Saunders; 2018 Aug 1 [cited 2019 Mar 13];44(8):1241-6. Available from: https://www.sciencedirect.com/science/article/pii/ S0748798318310138. This large retrospective study highlighted the poor positive predictive value of radiological lymph node staging, showing a PPV of only $56 \%$. The authors compared this with "flipping a coin".

25. Al-Sukhni E, Milot L, Fruitman M, Beyene J, Victor JC, Schmocker S, et al. Diagnostic accuracy of MRI for assessment of T category, lymph node metastases, and circumferential resection margin involvement in patients with rectal cancer: a systematic review and meta-analysis. Ann Surg Oncol [Internet]. SpringerVerlag; 2012 Jul 20 [cited 2019 Feb 25];19(7):2212-23. Available from: http://www.springerlink.com/index/10.1245/ s10434-011-2210-5.

26. Smith NJ, Barbachano Y, Norman AR, Swift RI, Abulafi AM, Brown G. Prognostic significance of magnetic resonance imaging-detected extramural vascular invasion in rectal cancer. $\mathrm{Br}$ J Surg [Internet]. 2007 Oct 11 [cited 2016 Dec 15];95(2):229-36. Available from: http://www.ncbi.nlm.nih.gov/pubmed/17932879.

27. Chand M, Evans J, Swift RI, Tekkis PP, West NP, Stamp G, et al. The prognostic significance of postchemoradiotherapy highresolution MRI and histopathology detected extramural venous invasion in rectal cancer. Ann Surg [Internet]. 2015 Mar [cited 2016 Dec 1];261(3):473-9. Available from: http://content.wkhealth.com/ linkback/openurl?sid=WKPTLP:landingpage $\&$ an $=00000658$ 201503000-00011.

28. Heald RJ. The "Holy Plane" of rectal surgery. J R Soc Med [Internet]. Royal Society of Medicine Press; 1988 Sep [cited 2019 Feb 26];81(9):503-8. Available from: http://www.ncbi.nlm.nih. gov/pubmed/3184105.

29. Taylor FGM, Quirke P, Heald RJ, Moran BJ, Blomqvist L, Swift IR, et al. Preoperative magnetic resonance imaging assessment of circumferential resection margin predicts disease-free survival and local recurrence: 5-year follow-up results of the MERCURY study. J Clin Oncol [Internet]. 2014 Jan 1 [cited 2016 Dec 14];32(1):3443. Available from: http://www.ncbi.nlm.nih.gov/pubmed/ 24276776.

30. Quirke P, Steele R, Monson J, Grieve R, Khanna S, Couture Jet al. Effect of the plane of surgery achieved on local recurrence in patients with operable rectal cancer: a prospective study using data from the MRC CR07 and NCIC-CTG CO16 randomised clinical trial. Lancet (London, England) [Internet]. Elsevier; 2009 Mar 7 [cited 2019 Feb 26];373(9666):821-8. Available from: http:// www.ncbi.nlm.nih.gov/pubmed/19269520.

31. Knijn N, van Erning FN, Overbeek LIH, Punt CJA, Lemmens VEPP, Hugen N, et al. Limited effect of lymph node status on the metastatic pattern in colorectal cancer. Oncotarget [Internet]. 2016 May 30 [cited 2016 Oct 17]; Available from: http://www. oncotarget.com/abstract/9064.

32. Knijn N, Mekenkamp LJM, Klomp M, Vink-Börger ME, Tol J, Teerenstra S, et al. KRAS mutation analysis: a comparison between primary tumours and matched liver metastases in 305 colorectal cancer patients. Br J Cancer [Internet]. Nature Publishing Group; 2011 Mar 15 [cited 2016 Aug 12];104(6):1020-6. Available from: http://www.ncbi.nlm.nih.gov/pubmed/21364579.

33. Naxerova K, Reiter JG, Brachtel E, Lennerz JK, van de Wetering $\mathrm{M}$, Rowan A, et al. Origins of lymphatic and distant metastases in human colorectal cancer. Science (80- ) [Internet]. 2017 Jul 7 [cited 2017 Oct 6];357(6346):55-60. Available from: http://www.ncbi. nlm.nih.gov/pubmed/28684519. This landmark paper assessed the phylogenetic concordance of LNM and distant metastases and showed that LNM could not have been the precursors of the metastases in $2 / 3$ of cases. This questions the long-held assumption that LNM have a major role in distant tumour dissemination.

34. Nagtegaal ID, Schmoll H-J. Colorectal cancer: what is the role of lymph node metastases in the progression of colorectal cancer? Nat Rev Gastroenterol Hepatol [Internet]. Nature Publishing Group; 2017 Sep 20 [cited 2019 Mar 13];14(11):633-4. Available from: http://www.nature.com/doifinder/10.1038/nrgastro.2017.122.

35. Ullah I, Karthik G-M, Alkodsi A, Kjällquist U, Stålhammar G, Lövrot $\mathrm{J}$, et al. Evolutionary history of metastatic breast cancer reveals minimal seeding from axillary lymph nodes. J Clin Invest [Internet]. 2018 Apr 2 [cited 2019 May 9];128(4):1355-70. Available from: https://www.jci.org/articles/view/96149.

36. ClinicalTrials.gov [Internet]. Bethesda (MD): National Library of Medicine (US). ID: NCT03303547 concordance in MRI and pathology diagnosis of Extranodal tumour deposits - full text view - ClinicalTrials.gov [Internet]. [cited 2019 Mar 14]. Available from: https://www.clinicaltrials.gov/ct2/show/NCT03303547?term $=$ brown+comet\&rank=1.

Publisher's Note Springer Nature remains neutral with regard to jurisdictional claims in published maps and institutional affiliations. 